\title{
Computer Applications in Power Electronic Systems
}

\author{
Mahendran Nagalingam ${ }^{1}$, Dr.G.Gurusamy ${ }^{2}$ \\ 1-Research Scholar Bannari Amman Institute of Technology, Sathyamangalam, Tamil Nadu, India, \\ 2- Prof/Dean, Bannari Amman Institute of Technology, Sathyamangalam, Tamil Nadu, India,
}

\begin{abstract}
Computer Applications in Power System is place an important role to verify the system performance and real time monitoring systems. Most of the Electrical system uses LABVIEW and other software to monitor real time electrical transition. In this paper we are focusing on Power Electronic Conversion system. Power Electronic System is easily simulated using MATLAB Software. Here we are giving easy simulation of Matrix converter and its result. Clean power development in power electronic system is an emerging area of research in Electrical Engineering. Most of the power electronic system introduces harmonics in power system. Elimination of harmonic is a tedious process. Different control strategy should be developed to reduce the harmonic. In Rectifier fed Inverter system has many disadvantages because of DC link filter. Matrix converter avoids this DC link filter and output approaches input. In this paper we have simulated Single phase Matrix Converter. Computer based simulation using MATLAB and Real Time implementation using PIC89C51 validate its originality. Finally we have compared different values of Harmonics.
\end{abstract}

KEYWORDS: Matrix Converter, Clean Power, Rectifier fed Inverter, Harmonics, DC link filter, PIC89C51, Computer Applications.

\section{INTRODUCTION}

Total Harmonic Distortion (THD) is the most common power quality index to describe the quality of power electronic converter. In general, all the output voltage of power electronic converters is not purely sinusoidal. For inverter application, THD represents how close the ac output waveform with pure sinusoidal waveform. A High quality matrix converter system should have low THD. Various study has been made on harmonic losses at electrical machine, it reveals that, presence of harmonic current in winding causes an increased copper loss [1]. The stator copper loss on a non sinusoidal supply is proportional to the square of the total rms current [2]. The core loss in the machine is increased by the presence of harmonics in the supply voltage and current. Magnitude of harmonic loss obviously depends upon the harmonic content of the motor voltage and current. Large harmonic voltage at low harmonic frequencies cause significantly increased machine loss and reduced efficiency [3]. Many theoretical studies have been investigated on matrix converter but have found very few practical applications in power electronics. Matrix converter has been known to offer an "all silicon" solution for AC-AC conversion, removing the need for reactive energy storage components used in conventional rectifier-inverter based system. Its topology was first proposed by Gyugyi in 1976[1]. The circuit is arranged such that any output lines of the converter can be connected to any input lines. Obviously, published studies have mainly dealt with three-phase circuit topologies. The main purpose of this paper is to describe successful implementation of the SPMC that had been conceived, designed and realized by synthesizing the output using the well-known SPWM technique
[2]. In this work, the micro controller was used to produce the sinusoidal pulse width modulation (SPWM) switching with SCR's as the SPMC power switching device. Prior to hardware implementations, simulations were performed to predict the behavior. A laboratory model test-rig of the SPMC was then constructed to perform investigation [3], [4].Industrial application of matrix converter is still very limited because of some practical issues like common mode voltage effects, high susceptibility to input power disturbances and low voltage transfer ratio [5]. In order to extend the horizon of matrix converter into several distributed power sources application, the objective of this research work is to simulate practical matrix converter. Objective of this research is to propose a PWM strategy to reduce THD, which is reported to $\mathrm{R}$. These results are compared with various operating frequencies. Single phase matrix converter is developed and simulated using MATLAB Simulink and this result is verified using real time system.

\section{DIRECT AC TO AC CONVERTER}

The AC/AC converters are commonly classified into indirect converter which utilizes a dc link between the two ac systems and direct converter that provides direct conversion. Indirect converter consists of two converter stages and energy storage element, which convert input ac to dc and then reconverting dc back to output ac with variable amplitude and frequency [9]. The operation of these converter stages is decoupled on an instantaneous basis by means of energy storage element and controlled independently, so long as the average energy flow is equal. Figure 1 shows single phase matrix converter arrangement.

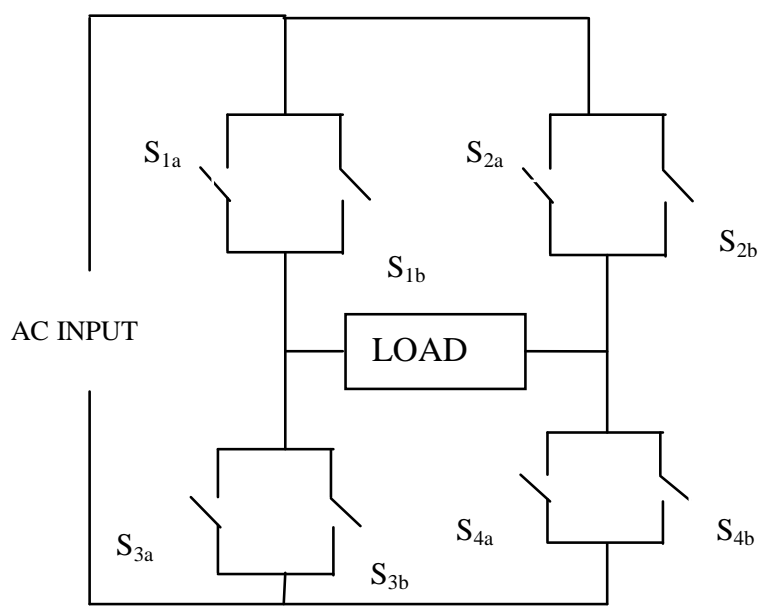

Fig. 1. Single Phase Matrix Converter: Where S1a refers Bidirectional switch 


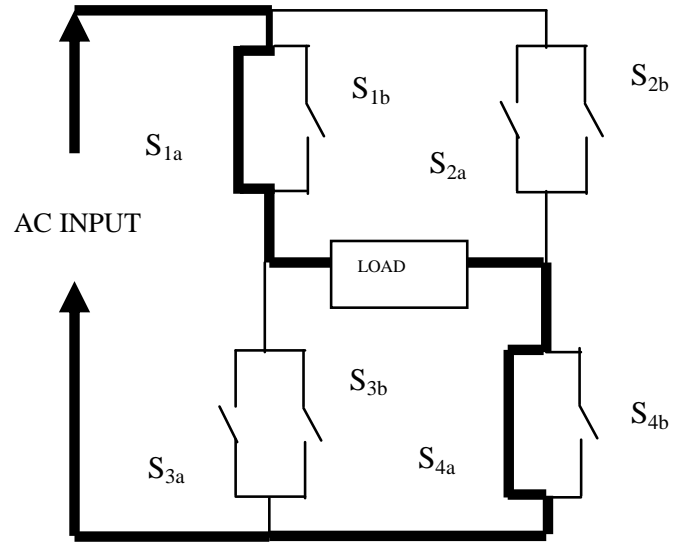

Fig. 2. Single Phase Matrix Converter: Where S1a and S4a Switched On (Positive Half Cycle)

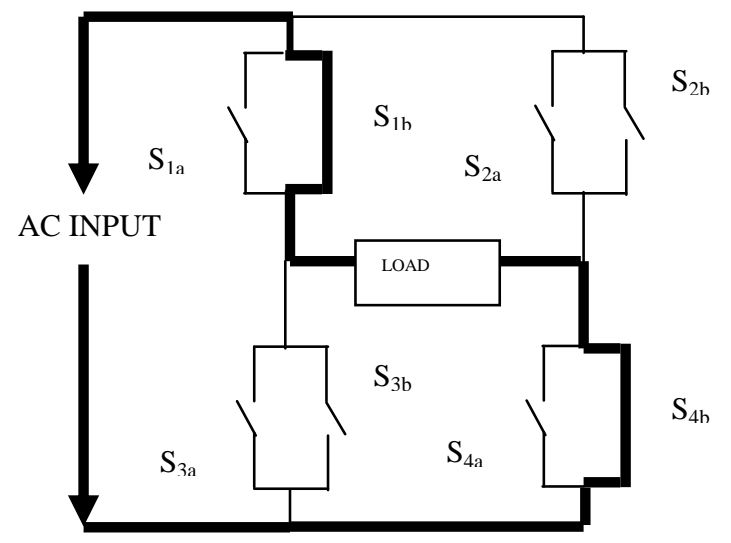

Fig. 3. Single Phase Matrix Converter: Where S1b and S4b Switched On (Negative Half Cycle)

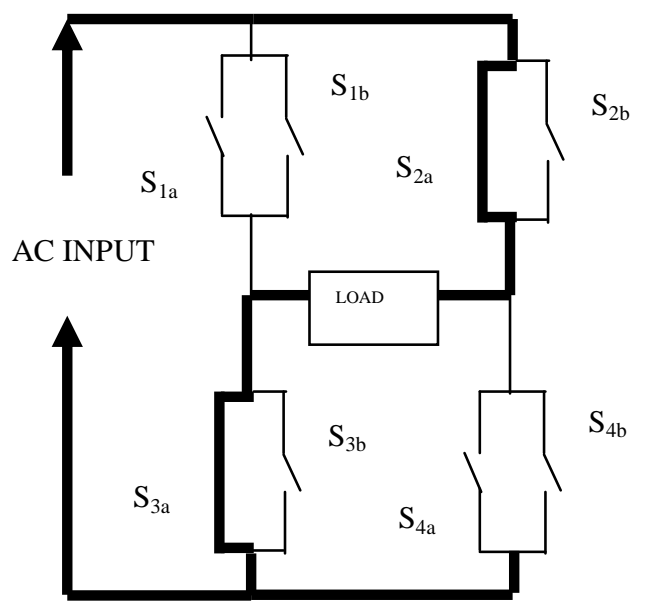

Fig. 4. Single Phase Matrix Converter: Where S2a and S3a Switched On (Positive Half Cycle)

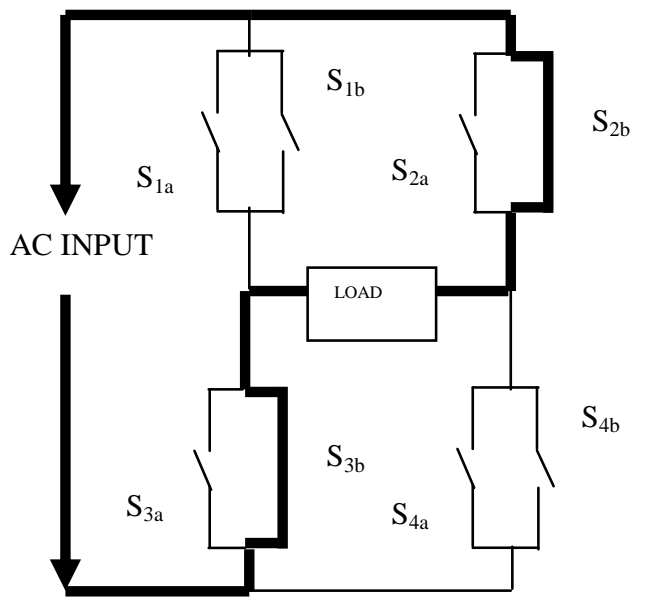

Fig. 5. Single Phase Matrix Converter: Where S2a and S3a Switched On (Negative Half Cycle)

The Matrix Converter requires a bidirectional switch capable of blocking voltage and conducting current in both directions. Unfortunately there is no discrete component that fulfils these needs. To overcome this problem the common emitter anti-parallel IGBT [6], diode pair is used. Diodes are in place to provide reverse blocking capability to the switch module.

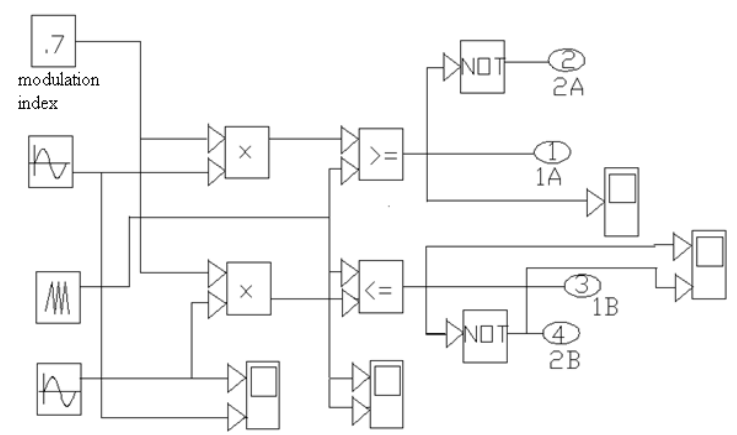

Fig. 6. Generation Sinusoidal pulse width modulation

Figure 2 to Figure 5 shows that Operation of matrix converter for 4 modes of operation. Figure 6 shows that generation of Sinusoidal Pulse width modulation using MATLAB. This may be implemented using $\mathrm{C}$ language. In this research we are using special purpose IC which has inbuilt function to generate Sine PWM.

\section{DIFFERENT MODULATION SCHEME}

A sinusoidal ac voltage source having an amplitude $\mathrm{V}_{1}$ and angular frequency $\mathrm{w}_{1}\left(2 \Pi \mathrm{f}_{1}\right)$ is connected to the input terminal of matrix converter. This is applied sinusoidal voltage is converted into an output voltage with amplitude of $\mathrm{V}_{0}$ and angular frequency $\mathrm{w}_{0}\left(2 \Pi \mathrm{f}_{0}\right)$, which is applied to the load. Upper limit of the range of variation of the output frequency lies at a point lower than the input frequency [7].

$$
\begin{aligned}
& \mathrm{V}_{\mathrm{ABC}}=\mathrm{K}_{\mathrm{i}} \mathrm{e}^{\mathrm{j}\left(\mathrm{w}_{\mathrm{t}} \mathrm{t}+\Phi\right)} \\
& \mathrm{V}_{\mathrm{UVW}}=\mathrm{K}_{0} \mathrm{e}^{\mathrm{j}\left(\mathrm{w}_{0}^{\mathrm{i}} \stackrel{\mathrm{i}}{\mathrm{t}+\Phi}\right)}
\end{aligned}
$$


Control principle( $\mathrm{S}(\mathrm{t}))$

$S(t)=\frac{K_{0} e^{j\left(w_{0} t+\phi_{0}\right)}}{K_{i} e^{j\left(w_{i} t+\phi_{i}\right)}}$

Maximum voltage transfer ratio $50 \%$ is possible in Venturini Algorithm. An improvement in the achievable voltage ratio to $\frac{\sqrt{3}}{2}$ (for $87 \%$ ) is possible by adding common mode voltage to the target output. We can investigate these voltage transformation ratio based on following theoretical analysis. There are different modulation techniques available from Venturini invention (1980) [9]. Implementation of ventrini algorithm is difficult calculation. We are looking forward towards simple algorithm and improved voltage transformation ratio [10]. Following switching equations will explain about output voltage relationship and review of switching techniques. Equation 1,2 and 3 shows that basic modulation development.

\subsection{Venturini modulation method (Venturini first method)}

$m_{k j}=\frac{t_{k j}}{T_{s e p}}=\frac{1}{3}\left[1+\frac{2 v_{k} v_{j}}{v^{2}{ }_{i m}}\right]$,

for $\mathrm{k}=\mathrm{A}, \mathrm{B}, \mathrm{C}$ and $\mathrm{j}=\mathrm{a}, \mathrm{b}, \mathrm{c}$

Voltage transformation ratio is $50 \%$.From equation (4) second term $\mathrm{q}=1 / 2$.

\subsection{Venturini Optimum method (Venturini Second method)}

Employs common mode addition and maximum transformation ratio is $87 \%$. This is also known as displacement factor control [11]. Displacement factor control can be introduced by inserting a phase shift between the measure input voltages and inserted voltage $\left(v_{k}\right)$. Equation 5 shows that relationship between modulation index and maximum voltage transformation.

$m_{k j}=\frac{t_{k j}}{T_{\text {sep }}}=\frac{1}{3}\left[1+\frac{2 v_{k} v_{j}}{v_{\text {im }}^{2}}+\frac{4 q}{3 \sqrt{3}} \sin \left(\omega_{i} t+\beta_{k}\right) \sin \left(3 \omega_{i} t\right)\right]$,

For $\mathrm{k}=\mathrm{A}, \mathrm{B}, \mathrm{C}$ and $\mathrm{j}=\mathrm{a}, \mathrm{b}, \mathrm{c}$

$\beta_{k}=0,2 \Pi / 3$ for $\mathrm{k}=\mathrm{A}, \mathrm{B}, \mathrm{C}$

\subsection{Scalar Modulation method:}

Actuation signals are calculated directly from measurement of input voltages. Voltage transformation ratio is $87 \%$.

$$
m_{k j}=\frac{t_{k j}}{T_{\text {sep }}}=\frac{1}{3}\left[1+\frac{2 v_{k} v_{j}}{v^{2}{ }_{i m}}+\frac{2}{3} \sin \left(\omega_{i} t+\beta_{k}\right) \sin \left(3 \omega_{i} t\right)\right]
$$

This method yields virtually identical switch timings to the optimum Venturini method [12]. The maximum output voltage $\left(\mathrm{q}=\frac{\sqrt{3}}{2}\right)$ are identical. Only the difference between the methods is that the right most term addition is taken pro rata with $\mathrm{q}$ in the Venturini method. Equation 6 shows that relationship between modulation index and maximum voltage transformation.

\subsection{SPVM}

Space vector pulse width modulation is applied to output voltage and input current control. This method is advantage because of increased flexibility in choice of switching vector for both input current and output voltage control can yield useful advantage under unbalanced conditions.

\subsection{Indirect Modulation method}

This method aims to increase the maximum voltage ratio above $86.6 \%$ limit of other methods.

$$
v_{o}=\left(A v_{i}\right) B=\frac{3 K_{A} K_{B} V_{i m}}{2}\left[\begin{array}{c}
\cos \left(\omega_{i} t\right) \\
\left.\cos \left(\omega_{i} t+2 \pi / 3\right)\right] \\
\cos \left(\omega_{i} t+45 \pi / 3\right)
\end{array}\right]
$$

Voltage ratio $\mathrm{q}=3 \mathrm{~K}_{\mathrm{A}} \mathrm{K}_{\mathrm{B}} / 2$. Clearly $\mathrm{A}$ and $\mathrm{B}$ modulation steps are not continuous in time as shown above.

$$
\begin{array}{ll}
\mathrm{K}_{\mathrm{A}} & =2 \operatorname{sqrt}(3) \mathrm{V}_{\mathrm{im}} / \Pi \\
\mathrm{K}_{\mathrm{B}} & =2 / \Pi \\
\text { Then, q } & =6 \operatorname{sqrt}(3) / \Pi^{2}=105.3 \%
\end{array}
$$

The voltage output is greater than the previous method. For the values $\mathrm{q}>0.866$, the mean output voltage no longer equals the target output voltage in each switching interval. This inevitably leads to low frequency distortion in the output voltage and /or the input current compared to other methods with $\mathrm{q}<0.866$. For $\mathrm{q}<0.866$, the indirect method yields very similar results to the direct methods. Equation 7 to 10 shows that relationship between modulation index and maximum voltage transformation [13], [14]. We are using Sinusoidal pulse width modulation is used to control Switching Devices.

\section{REAL TIME ENVIRONMENT UISNG MATLAB AND PIC CONTROLLER}

Figure 7 shows Power and Control circuit implementation in real time environment.

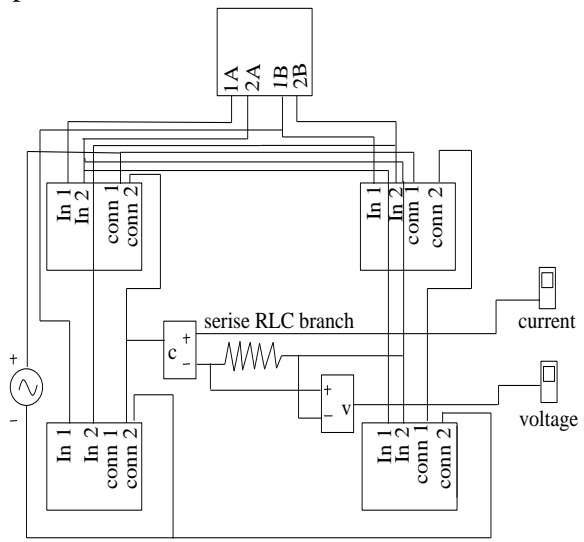

Fig. 7. Simulation of Single Phase Matrix Converter Using MATLAB

A Simple circuit is developed using available components in the laboratory. The control circuit consists of Diode Bridge, counter circuit and amplifier circuit. When 12V AC supply is given, the bridge rectifier converts it into $12 \mathrm{~V} \mathrm{DC}$. The bridge rectifier consists of IN 4007 Diode. The positive series regulator (7805) steps down the output of bridge rectifier to $5 \mathrm{~V}$. This $5 \mathrm{~V}$ voltage is given as the supply to the counter circuit which gives square pulse as output. The counter circuit consists of synchronous counter (IC). For each half cycle of the input voltage the counter produces the square pulses to trigger the thyristors correspondingly. This output is given to amplifier circuit. The amplifier circuit consists of four Darlington pair amplifiers which amplify the current in order to trigger the corresponding SCRs. The Darlington pair consists of transistor (SL 100). The output of each Darlington pair is given to a pulse transformer $(1: 1: 1)$. The voltage in the primary of the transformer is induced in the secondary which will trigger the SCRs in the sequence mentioned above. Above circuit arrangements are shown in Figure 8. 


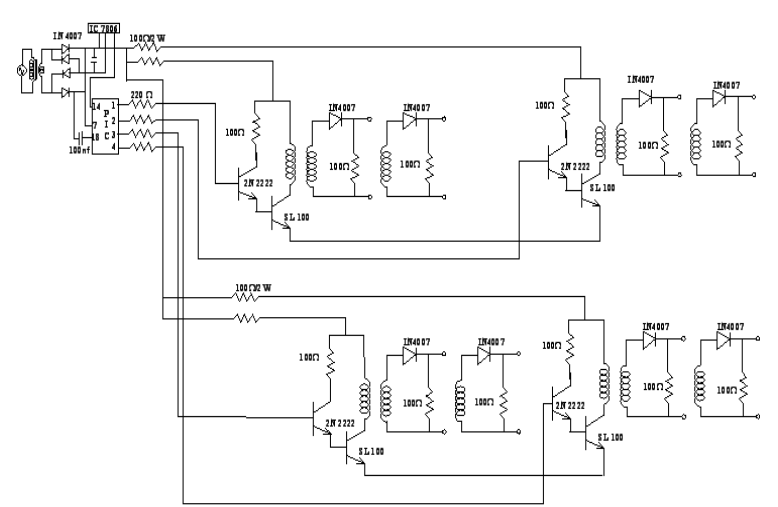

Fig .8. Control Circuit

The micro controller that has been used for this research is PIC series. PIC micro controller is the first RISC based microcontroller fabricated in CMOS that uses separate bus for instruction and data. The additional advantage of CMOS has noise to immunity lesser than other fabrication techniques. Various micro controllers offer different kinds of memories. EEPROM, EPROM, FLASH etc., some of the memories of which FLASH is the most recently developed. Technology that is used in PIC16F877A is FLASH technology, so that data is retained even when the power is switched OFF. Easy programming and erasing are other features of PIC16F877A. A simple algorithm to develop Sinusoidal Pulse Width Modulation is shown in Appendix A. Above programs are developed using inbuilt PWM instruction.

\section{RESULT AND ANALYSIS}

First single phase matrix converter is simulated for R load. This result is compared with Matlab Simulation results. Real time measurement is following the computer simulation. This proves that Matrix converter is a technology which is used to convert direct $\mathrm{AC}$ to $\mathrm{AC}$ conversion. This analysis can be done from Figure 9 and Figure 10.Next set of analysis is High voltage transformation ratio. This is indirectly proved here. If total harmonic is reduced then High voltage will be transformed to output side. Following section prove the above statement. For the sake of analysis we took only Output voltage.

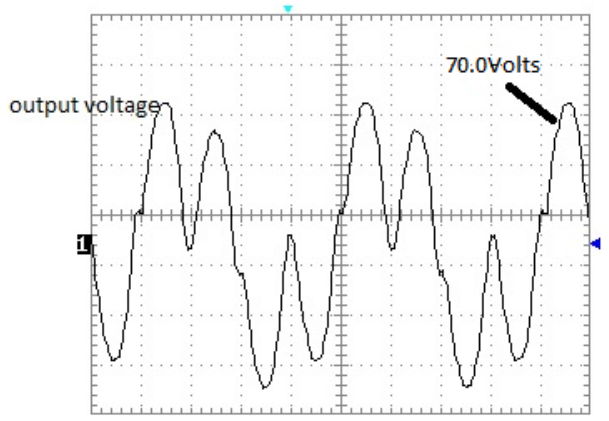

Fig. 9. Practical Output voltage for $25 \mathrm{~Hz}$ (Measured using Scientific DSO)

Result is simulated for $25 \mathrm{~Hz}$ output frequency. In case of $25 \mathrm{~Hz}$ Output voltage is similar to that of Figure 9 (Practical measured value) and Figure 10(Matlab simulation). But there is no change in shape of the output. But RMS value of output voltage and output current are varying. This may reduce the voltage transformation ratio of the converter. But our aim is fulfilled.

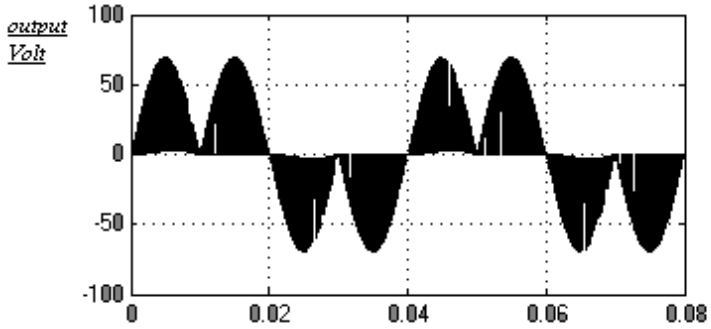

Fig.10. Output Voltage for $25 \mathrm{~Hz}$ (Measured using computerized simulation-Matlab)

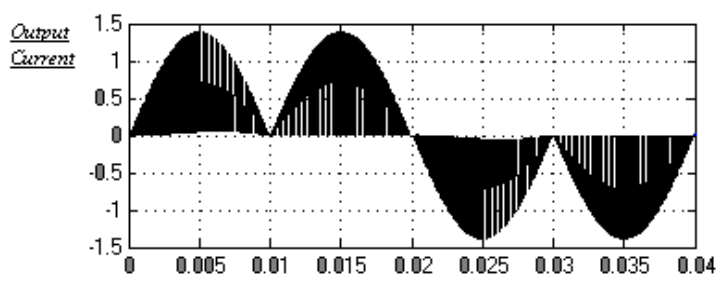

Fig. 11. Output Current $25 \mathrm{~Hz}$

Table 1 shows the open loop simulation of matrix converter with different load conditions. THD are measured for open loop Space vector control method.By changing the switching behavior of the inverter, the audible noise can also be influenced and therefore be minimized. Space Vector Modulation provides excellent output performance, optimized efficiency, and high reliability compared to similar inverters with conventional Pulse Width Modulation.

Table 1 THD comparision R,RL and Motor load(Open loop simulation), without output filter

\begin{tabular}{|l|l|l|l|}
\hline Parameter & R Load & RL Load & $\begin{array}{l}\text { Motor } \\
\text { Load }\end{array}$ \\
\hline $\begin{array}{l}\text { Switching } \\
\text { Frequency }\end{array}$ & $16 \mathrm{KHz}$ & $16 \mathrm{KHz}$ & $16 \mathrm{KHz}$ \\
\hline $\begin{array}{l}\text { Output } \\
\text { THD }\end{array}$ & $65.64 \%$ & $22.05 \%$ & $4.9 \%$ \\
\hline $\begin{array}{l}\text { Input } \\
\text { THD }\end{array}$ & $22.7 \%$ & $22.59 \%$ & $22.43 \%$ \\
\hline
\end{tabular}

\section{CONCLUSION}

In this paper a Single phase MC was proposed. Voltage control was implemented using Sinusoidal Pulse Width Modulation. For various values of frequency output is measured. Simulation results are verified with respect to hardware implementation. Safe commutation principle also implemented. This principle may be implemented for three phase matrix converter. Further this simulation may be extended to inductive load and better result may be implemented using space vector pulse width modulation. If we are very good at implementation of matrix converter control principle Phase Phasor vector control also possible. Important point to be noted that during the identification of sectors it is tedious process. It may be made simple if this algorithm is developed using Digital Signal Processor.

\section{REFERENCES}

[1] V. Ramanarayanan, Matrix converter, "Proceedings of national workshop on power electronics NWPE2006", NAMPET, IIT Kanpur. 
[2] P.D.Ziogas, S.I.Khan and M.H. Rashid, "Analysis and design of forced commutated cycloconmverter structures with improved transfer characteristics", IEEE transactions on Industrial Electronics, vol.IE-33, August 1986, 271-280.

[3] Patrick W. Wheeler, Jose Rodriguez, Jon C .Clare , Lee Empreingham and Alejandro Weinstein,"Matrix Converters: A Technology Review", IEEE Transactions on Industrial Electronics, Vol.49,No.2,April 2002,282-285

[4] C. L. Weft and C. D. Schauder, "Theory and design of 30HP matrix converter", IEEE Transactions on Industrial Applications, Vol.28, No 3, PP 546-551.

[5] N. Mahedran and G. Gurusamy, "THD Analysis of Matrix converter fed load", Proceedings of International Conference on Power Electronics and Drive Sysems (IEEE PEDS2009TAIWAN), Page(s): $828-832$

[6] N. Nquyen-Quag, D. A. Stone, C.M. bingham and M.P. Foster, "Single phase matrix converter for radio frequency induction heating", IEEE SPEEDAM 2006, S18-S28.

[7] T. N. Wheeler, J. C. Clare, L.de Lillo and K. J. Bradley," A comparison of reliability of a matrix converter and a controlled rectifier inverter", EPE 2005, P1-P7.

[8] M. S. N. Romli, Z. Idris, A. Saparaon and M. K. Hamazah,"An area efficient sinusoidal Pulse Width Modulation(spwm)Technique for single phase matrix converter(spmc)", IEEE 2008, Page 1163-1168.

[9] S. Z. Mahammad Noor, R. Baharom, N. S. Damanhuri and M. K. Hamzah,"Single phase inverter with fully controlled regenerative capability using single phase matrix converter", IEEE 2008, page 934-939.

[10] Siti Zahiha Mohammad Noor, Mustafar Kamal Itamzah and Ahmaed Farid Abidin," Modelling and Simulation of a DC Chopper using Single phase matrix converter topology", IEEE PEDS 2005, Page 827-832.

[11] Mustafar kamal Hamzah, Mohamad Fadzil Saidan,"Application of single phase matrix converter topology in UPS circuit incorporating unity Power factor control", IEEE ICIEA 2006.

[12] Malcolm tabore, Cyril Spiteri Staines , Joseph, "Low cost three phase to single phase matrix converter", IEEE ICIT 2004, Page 474-479.

[13] Zahirudin Idris, Siti Zaliha Mohammed Noor, Mustafar Kamal hamzah," Safe Commutation Strategy in single phase matrix converter", IEEE PEDS 2005, Page 886-891.

[14] N.Mahendran, Dr. G.Gurusamy, “ Modelling and Simulagtion of Sine wave to Sine wave converter for AC drive-A technology reviw" Proceedings of the International Conference on ICMEE 2009,Chennai, India, 24 - 26 July 2009, (pp 285-289).

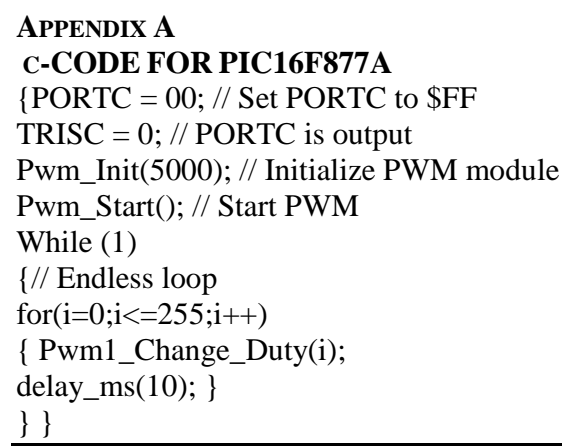

APPENDIX A

C-CODE FOR PIC16F877A

$\{$ PORTC $=00 ; / /$ Set PORTC to \$FF

TRISC $=0 ; / /$ PORTC is output

Pwm_Init(5000); // Initialize PWM module

Pwm_Start(); // Start PWM

While (1)

\{// Endless loop

for $(\mathrm{i}=0 ; \mathrm{i}<=255 ; \mathrm{i}++)$

$\{$ Pwm1_Change_Duty(i);

delay_ms $(10)$;

\} \}

\section{APPENDIX B}

Design Parameters

Open circuit voltage $\quad 5-10 \mathrm{~V}$

Ignition current $\quad 10 \mathrm{~mA}-3 \mathrm{~A}$

Rise time $0.25-3.3 \mu \mathrm{s}$

Pulse duration up to $\quad 10 \mathrm{kHz}$

Pulse frequency for data transmission up to $500 \mathrm{kHz}$

\section{AUTHORS DETAILS}

N.Mahendran received his BE in Electrical and Electronics Engineering from the Madras University in 2000, his M.Tech in Control Systems and Instrumentation Engineering from the University of SASTRA, Thanjavur in 2004 and he is pursuing $\mathrm{PhD}$ in Electrical Engineering from the Anna University-Chennai. $\mathrm{He}$ is currently a Research Scholar of Electrical Engineering at Bannari Amman Institute of Technology and his primary profession is teaching at Maha college of Engineering, Salem. His research interests include machine controls, electric drives, and artificial intelligence and control systems.

Dr.G.Gurusamy obtained his Pre University education at St Johns College, Palayankottai and Trinelvelli district. He joined PSG College of Technology, Coimbatore, in the year 1962 to pursue his Engineering course. He was Graduated in Electrical Engineering in 1967.Latter he obtained his M.E. (Applied Electronics) in 1972 and Ph.D in Control Systems in 1983. He has more than 30 years of teaching Experience in PSG college of Technology. He is currently working as Dean of Department of Electrical and Electronics Engineering in Bannari Amman Institute of Technology, Sathyamangalam. His field of interest is advanced control, Power Quality, Digital control, Optimization and Bio medical Electronics. 